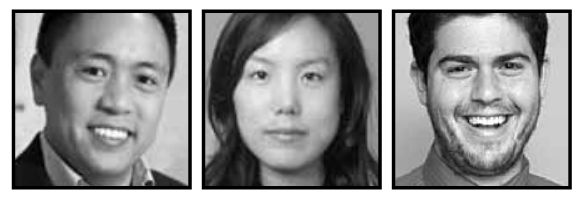

\title{
What Twitter Will and Will Not Do: Theorizing About Teachers' Online Professional Communities
}

\author{
Vincent Cho, Jina Ro, and Josh Littenberg-Tobias, Boston College
}

\begin{abstract}
A growing hope is that Twitter and similar technologies will enhance teachers' professional growth by allowing them to collaborate and support each other online. In this conceptual paper, we evaluate the potential of such claims, theorizing about the relationships among technologies, practice, and communities of practice. Specifically, we demonstrate how the concepts of materiality and sociomateriality can be applied toward understanding and researching teachers' professional communities on Twitter. Materiality refers to the physical or digital components of a technology. Sociomateriality refers the social practices and contexts shaping one's sense of a technology.
\end{abstract}

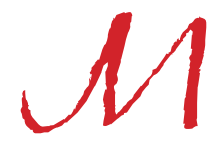

any educators are hopeful that Web 2.0 technologies have the potential to reshape schooling. Web 2.0 technologies (e.g., wikis, blogs, social networking sites) offer unprecedented ways for people to interact collaboratively, to create new content, and to leverage a diversity of media (e.g., text, audio, video). Such interactions can occur at any time and from anywhere around the world. Not surprisingly, educational scholars have initially sought to understand the potential of Web 2.0 by focusing on its potential contributions to instructional practices (Greenhow, Robelia, \& Hughes, 2009; Hughes \& Narayan, 2009; Nash, 2011).

However, suggestions have also emerged that Web 2.0 could also serve as a catalyst for collaboration and professional growth among teachers (Burden, 2010). Although plausible, this possibility yet deserves additional, deliberate examination. Certainly, this argument has gained popularity among professionals in the field. In the trade literature, this enthusiasm has been exemplified by arguments about the 
power of "personal learning networks" (PLNs) (Richardson \& Mancabelli, 2011) and of being a "connected educator" (Nussbaum-Beach \& Hall, 2012). Proponents of personal learning networks argue that Web 2.0 technologies provide educators with robust knowledge resources. Information streams can be tailored toward one's interests. Networks of professional relationships can be accessed for support. The imagined result is not only teacher professional growth, but also fundamental changes to the nature of schooling.

Indeed, the rhetoric around Twitter (a microblogging service) seems to exemplify such hopes. Launched in 2006, Twitter characterized itself as a way to "Find out what's happening, right now, with the people and organizations you care about" (twitter.com). Since then, Twitter has been especially touted for its information-sharing capacities. For example, Howard et al. (2011) describe Twitter's role in shaping and coordinating political engagement throughout the Arab Spring uprisings. What's more, Kwak, Lee, Park, and Moon (2010) describe the remarkable speed with which news on Twitter can travel among millions of users around the world. This optimism has been extended toward the sharing of professional knowledge. Couros and Jarret (2012) describe how Twitter helps educators connect with:

Professionals with common interests who use Twitter to trade information, share resources, ask and answer questions, and debate and discuss education issues of the day... Educators are able to assemble a collection of literally "the best and the brightest" practitioners from around the world, individuals with whom the average teacher usually would never have the chance to interact with or learn from. (p. 149)

Although such accounts are encouraging, the promises around Twitter, PLNs, and the role of Web 2.0 technologies have yet to be studied empirically. While scholars have long acknowledged the importance of professional communities and relationships in the growth of educators (Barth, 1990; Fullan, 2002; McDaniel \& Weick, 1989; Talbert, 2010), it is yet unclear what happens when educators attempt to translate those relationships into online interactions. Of additional concern, educational scholars and practitioners have too often assumed that simply adopting a technology is enough to "result" in changes to practice (Brooks, 2011; Cho \& Wayman, in press). Thus, scholars and practitioners alike could benefit from more accurate ways to understand what Twitter will and will not do for teachers' professional communities online. In order to develop such understandings, however, stronger theorizing about such issues is in order. 
We aim to support such theorizing by introducing education circles to concepts from information systems (IS) research. We first describe some of the hopes around teachers' professional communities online. Next, we illustrate how the concepts of materiality and sociomateriality can be used to illuminate different dimensions to Twitter and to its use. Subsequently, we discuss the implications that these dimensions may have for teachers' professional growth. Overall, these concepts serve as important reminders that educational change is not determined by the material presence of technologies per se, but rather by the values, motivations, and understandings of the people that use them. Applied to Twitter, this interpretivist approach sheds light on how the service's unique limitations could also be a source of strength and innovation among teacher communities online.

\section{Hopes Around Teachers' Communities Online}

In order to understand the proposed contributions of technologies to teachers' online professional communities, we first review conventional views regarding those communities. We follow this discussion by describing some of the hopes for how technologies like Twitter might support the development of professional communities.

\section{Traditional Views of Teacher Professional Communities}

Centered on the school, conventional teacher professional communities have been portrayed as venues in which teachers learn from one another, collaboratively improving their teaching practices (McLaughlin \& Talbert, 2006). These communities are often seen as a way to address the decontextualized nature of formal professional development. Because such resources are often developed by outside experts and geared toward schools generally, they may be perceived by teachers as falling short of the unique needs of their settings (Lieberman, 2000; McLaughlin \& Talbert, 2006). Schools differ in many ways that include sense of mission, levels of funding, and student population. Without connections to context and to practices in situ, professional development risks coming across as haphazard, fragmented, or irrelevant.

In contrast, professional communities provide a sphere for collective reflection and problem solving where people can not only process and apply formal training, but also share the unwritten insights that derive from experience (Brown 
\& Duguid, 1991; Nonaka, 1994). Teacher communities are characterized by teachers' active participation and collaboration in problem solving and decision making, a strong focus on teaching and learning, and an emphasis on developing evidencebased practice (Dufour, 2004; Hargreaves \& Fink, 2006). Thus, professional communities can be enriching both at the level of formally articulated knowledge, as well as at the level of craft knowledge. Together, these can improve practice.

Conventionally, teacher professional communities are bound by geography. In school-based communities, teachers will often gather in the same room or hall to discuss matters. Professional communities can also develop in workshop settings. For example, the National Writing Project is one notable example of such a teacher professional community in the United States. In both school and workshop settings, sharing space and having face-to-face interactions are the primary vehicles of building teacher professional communities.

\section{Hopes Around Web 2.0 and Twitter}

In contrast to traditional teacher professional communities, professional communities online may be geographically dispersed and interact asynchronously (Kozinets, 2009). To some, increased flexibility might be seen as increased time and capacity to connect with others. Indeed, proponents have argued that technological advancements will catalyze teachers' professional growth by providing a virtual space for professional communities to evolve (Lieberman, 2000; Li, Li, \& Sun, 2012; Schlager, Farooq, Fusco, Schank, \& Dwyer, 2009).

There are two major sets of arguments in favor of leveraging technologies in teacher professional communities. One set of arguments holds that online professional communities will increase the potential for dialogue among educators, thereby improving schooling (Burden, 2010). For instance, Li et al. (2012) describe how different dimensions of teacher peer coaching can be enhanced by Web 2.0 technologies. They argue that Web 2.0 technologies are supporting tools for teacher peer-coaching and should be selected carefully according to the objectives of peer coaching. For example, microblogging services such as Twitter can enhance interactions among teachers by allowing them to have more dialogue.

Another set of arguments claim that teachers will be able to access knowledge that is better tailored and more relevant to their everyday work. For example, Hew and Hara (2007) describe how teachers can leverage electronic mailing lists (listservs) to share opinions, suggestions, and practices. Similarly, Forte, Humphreys, and Park (2012) found that teachers used Twitter to develop new professional ties, 
leveraging those ties to increase their access to information and passing on that new information to others. By connecting teachers to teachers, scholars, and experts, such technologies have been portrayed as giving teachers access to more knowledge resources.

Together, both sets of arguments call attention toward the potential of technologies like Twitter. We now describe some ways to begin unraveling how much of this potential for teacher professional growth might be attributable to the technology itself.

\section{Materiality: Looking at Twitter}

One lens for understanding the potential of a technology is to examine its material characteristics. Indeed, this is the everyday way of understanding technology: To understand Twitter use, look at Twitter. Materiality involves the components of a technology, including how physical and/or digital materials are arranged into particular forms (Leonardi, 2012). Materiality includes the features and other "stuff" available to all users in the same way. Below, we attempt to demonstrate the concept of materiality by describing Twitter. Specifically, we describe the features and functions, as well as the access and interface that characterize some of Twitter's materiality.

\section{Features and Functions}

Twitter comes along with unique terminology. These terms can help to shed light on the material characteristics that are unique to the system.

\section{Tweets.}

Microblogging involves the rapid broadcast of short messages. With Twitter, each message or "tweet" is limited to 140 characters. These messages may contain hyperlinks to websites. One image that helps to describe how Twitter works is that of a series of radio towers, where each user serves as an individual beacon, sending out tweets. Other users can choose to listen in on tweets from other towers, gaining information or even retransmitting it to others. One chooses to listen to other users by "following" them. The default is for tweets not only to be broadcast to all of one's "followers," but also to be available publicly. Unlike other Web 2.0 technologies such as Facebook, being "followed" does not necessarily mean that one must follow back. In fact, the majority of Twitter relationships are one-way, with only $22 \%$ being reciprocal (Kwak et al., 2010). 


\section{Hashtags.}

Hashtags are a way to span boundaries across Twitter users and their sets of followers. Twitter hashtags are created by including the "\#" symbol before a word or phrase (e.g., \#edtech, \#StarTrek, \#AERA2014). These can serve as search terms or subject markers, reaching users who search for or monitor the hashtag in question. Hashtags allow one to reach a larger audience than one's standard network set of followers by cross-cutting according to a topic of interest. For example, Barkley (2012) describes how the hashtag \#cpchat served as a forum for administrators to connect to each other via Twitter.

\section{Mentions.}

Tweets may also "mention" other users by preceding a username with the “@” symbol (e.g., @DianeRavitch, @MCButtons). Not only does Twitter notify the user that he or she has been mentioned, but it also makes the tweet visible to that user's set of followers. Honeycutt and Herring (2009) describe how the @username function can shape information sharing on Twitter. For example, it can serve as a way to address or call upon a particular user, to direct others to take action, or to broadcast information to the other users' followers. This may also serve as way to increase one's own visibility and following (boyd, Golder, \& Lotan, 2010).

\section{Retweeting.}

Retweeting is a way to post to one's followers a tweet originating from another user. Because retweets can themselves be retweeted, information can cascade throughout Twitter to a large audience rapidly (Kwak et al., 2010). boyd et al. (2010) describe the ways in which users may modify messages before retweeting, as well as their purposes for retweeting. Retweets might add new content, or be intended to demonstrate agreement with, or to provide validation to, another user. Retweets may serve as triggers for social action by prompting users to rally and connect around a topic.

\section{Access and Interface}

Another dimension of Twitter's materiality is access and interface. Twitter can be accessed via its website, www.twitter.com. There also exist a host of thirdparty clients (e.g., TweetDeck, Hootsuite), mobile apps, and browser plug-ins. Thus, access is possible almost anywhere there is Internet access. It would seem that all one would need is a computer or mobile devices (e.g., smart phones, tablets). 


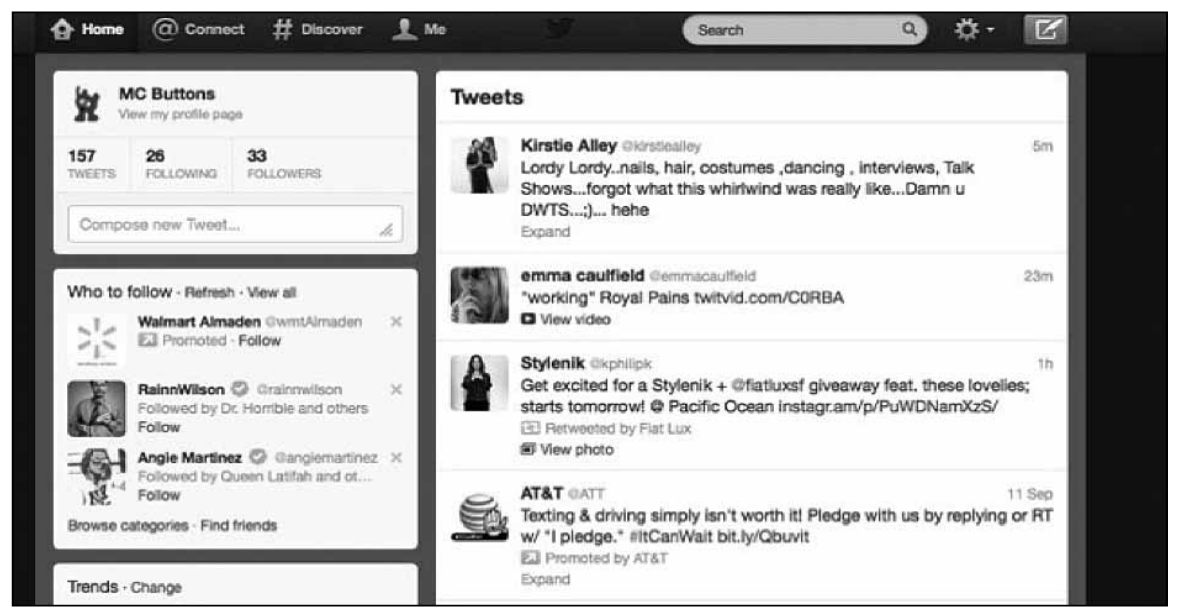

Fig. 1: Twitter screenshot. This figure illustrates the Twitter website interface.

Figure 1 provides a screenshot of the standard Twitter website interface (Twitter, 2012). Running across the top is a navigation bar that includes various icons, as well as a search box. Keywords, usernames, and Twitter hashtags are examples of information that might be queried using this function. At the top-left quadrant of the screen is publicly available profile information for the user, "MC Buttons." This includes a profile picture, number of tweets, number of users followed by MC Buttons, and MC Buttons's number of followers. Along the right-hand side of the screen are tweets from the users followed by MC Buttons. This stream of tweets is updated instantly and constantly, with the most recent tweet appearing at the top of the list. Clicking on a tweet expands the tweet so the user can see videos, pictures, or any information related to that tweet. Users can also interact with these tweets by hovering the mouse cursor over a tweet to reply, retweet, or mark as a favorite.

\section{Can Materiality Teach Us?}

Focusing on simply the materiality of a technology is not uncommon, but it can lead analysts to blind spots around the use and "effects" of a technology. Even among researchers, it can be difficult to think of a technology as more than just a "tool" (Orlikowski \& Barley, 2001; Orlikowski \& lacono, 2001). Focusing on the material characteristics of a tool draws one's attention to the espoused aims of a technology and its engineering (e.g., reducing burden, strengthening productivity; enhancing collaboration). Focusing on materiality alone assumes that the presence of a feature is sufficient to result in benefits. As a result, the problem of improvement might be envisioned as simply a problem of access to the tool. 
Thus, Twitter's material characteristics suggest great potential benefits. For example, several features of Twitter's design would seem to afford quick communication and wide-reaching connections with other professionals. Character limits, hashtags, and the ability to follow just about anyone are just a few of the features that bolster the vision of teachers connecting with other teachers rapidly, easily, and around mutual interests.

Indeed, much of the existing literature on teachers' professional communities online focuses only on the materiality and espoused intents of technologies, portraying Twitter and other systems simply as means toward more learning. Burden (2010) describes properties of Web 2.0 technologies that might contribute to teacher development. For example, he suggests that critical reflection might be served by teachers generating and publicly sharing their thoughts, such as via blogging. Similarly, Li et al. (2012) suggest that video chat technologies could open up opportunities for communication among teacher peer coaches. The question of whether, why, and how such potential is met, however, will not be easily answered by focusing on Twitter's or any other system's materiality.

Narrowly focusing on the material features of a technology has two main problems. First, it places materiality in the driver's seat for changes in practice, obscuring the role of human agency. Brooks (2011) observes that this kind of technological determinism is evident when district policy makers assume simply purchasing technology is sufficient to create "educational progress." Merely relying on material explanations for change fails to account for how technologies might be rejected or modified askew to their intended purposes. In other words, while the materials and design of a hammer may make it ideal for driving nails, this does not necessarily prevent it from being used as a paperweight (Leonardi, 2012). Twitter's benefits might not be about looking at Twitter. After all, just as Twitter has been cast as a professional development tool (Couros \& Jarrett, 2012; Richardson \& Mancabelli, 2011), it is also widely used for following celebrities (Kwak et al., 2010) and supporting political uprising (Howard et al., 2011). Twitter's material features may make all these things possible, but they do not explain how, why, or how effectively these different uses occur.

Second, a singular focus on materiality leads to assumptions that utility and practicality drive technology use. For example, educational scholars have promoted the notion that putting the "right data" in "better systems" will improve teachers' use of computer data systems (Hamilton et al., 2009; Means, Padilla, DeBarger, \& Bakia, 2009; Wayman, Stringfield, \& Yakimowski, 2004). This view of technology assumes 
that people will embrace the "best" tool for the job, because it is rational to do so. People, however, can act in non-rational ways. Leonardi (2009) describes how engineers can reject technologies, despite their potential benefits. Similarly, Wayman, Cho, and Johnston (2007) report about how teachers maintained traditional paper gradebooks simultaneously with online gradebooks, despite the burdens of the former. The same report also described how some schools doubled up on student information systems, implementing their own and the district's systems (despite the human and financial costs).

We propose that theorizing about teachers' professional communities online might be improved by considering Twitter and similar systems to be part of the context for where teacher learning communities could form. Materiality provides a starting point for understanding what might be possible, but it is the community that determines how, why, and to what degrees that materials are used.

\section{Sociomateriality: Looking at the People Side}

Twitter's material features are only one way to begin to understand its potential. The term "sociomateriality" refers to how social practices and context are inextricable from how a technology is used or understood (Leonardi, 2012). This goes beyond the intents espoused about a tool. Values, narratives, and relationships with others shape what people see in a technology, and consequently, what gets done in practice (Leonardi, 2009; Orlikowski, 1996; Cho \& Wayman, in press). This can happen in subtle and unexpected ways. If attention to materiality centers on the technical aspects of Twitter, attention to sociomateriality reveals many of the people issues that shape what happens with those characteristics and features.

In this section, we describe how the concepts of interpretive flexibility and structure help to illustrate the sociomaterial aspects of Twitter. After describing these two concepts, we apply each toward exploring the ways in which sociomaterial practices might affect teachers' professional learning via Twitter.

\section{Interpretive Flexibility}

One concept that is foundational to understanding sociomateriality is interpretive flexibility. As exemplified by studies about the Social Construction of Technology (SCOT), the same technology can mean different things to people in different 
social groups (Pinch \& Weibe, 1984). This emphasis on sensemaking underlines the influences of values, context, shared narratives, and social relations on technology use. For example, Cho and Wayman (in press) found that differences in teachers' use of the same computer data system could be attributed to differences in what they understood "data use" to be about. The same system could be used in one district as a tool for individualizing attention to student needs, while in another district it might be rejected as being irrelevant to student needs.

In ways that would not be predicted by focusing on Twitter's material features, the notion of interpretive flexibility allows the analyst to examine whether and how Twitter can mean different things to different people. There might not be one "Twitter" or one "best way" to use Twitter. How Twitter is defined (and used) might depend upon the goals, interests, and social context shared by the particular group or community in question. For teachers, those purposes could include sharing instructional wisdom, using Twitter as an instructional tool, or engaging in dialogue around educational politics and reform. These purposes might lead teachers to define Twitter as something that might not even occur to other users (e.g., students, administrators) or those with other interests (e.g., sports, investment, cooking). Below, we describe how this dynamic could shape practices online.

\section{Structure}

Structuration theory has been applied widely in studies of information systems and technologies (DeSanctis \& Poole, 1994; Jones \& Karston, 2008; Orlikowski, 1992). Structures are rules and resources that organize social systems. These rules and resources enable some activities while constraining others. Building upon the notion of interpretive flexibility, these structures might be associated with how people have made sense of their technologies. This sensemaking, however, is not just about the material features of a technology. Structures are part of the larger social fabric that includes institutions, policies, routines, and contexts around technology use (Bailey \& Barley, 2011; Davidson \& Chismar, 2007; Leonardi, 2009). Thus, some have asserted that structures have only a "virtual" existence, inextricable from the perceptions of the people engaged with them (Jones \& Karston, 2008; Orlikowski, 2000). Thus, socially constructed notions about a particular technology (e.g., what it does, doesn't do, or is good for) constitute structures that may influence users' practices.

For example, a person seeking to draw cash from an automatic teller machine (ATM) might incorrectly perceive that the machine is activated via touch screen, tapping it accordingly. However, it might also be that the material characteristics of the 
ATM do not afford touch screen use. Not realizing this, the person might even mash one's finger to the glass more strenuously or repeatedly - to no avail. These activities are not dependent on the technology's materiality, but rather on one's perception of an enabling structure in the material.

Equally important, another example of a structure is users' perceptions of community norms and rules. For example, an organization may have different social norms about when it is appropriate to ask a question by e-mail or by phone (WatsonManheim \& Bélanger, 2007). Orlikowski (1996) describes how the realization that a new electronic note-taking system had implications for problem solving and for one's status in the organization led to a host of changes in workers' practices. What people do with a technology is not just about whether the technology is capable of performing a specific action (its material characteristics). It is also about what activities people sense are enabled or constrained by perceived structures like norms and rules. One person might talk on her mobile phone outside of a library because of problems with reception, while another might do so in order to be (or seem) polite to others. The first might be responding to a perceived material constraint, while the second might be responding to both enabling and constraining social factors.

Indeed, Twitter may also be associated with certain social pressures. For example, the public nature of Twitter has been found to lead people to develop rules and routines around what types of content and information they post (Litt, 2012; Marwick \& boyd, 2010). Although adapting one's behavior to a context has been well documented in face-to-face conversations (Goffman, 1959; Schlenker, 1980), on Twitter this becomes more complicated. Communities and social contexts can easily overlap; multiple audiences might need to be imagined. As a result, Twitter users must balance the expectations of different potential audiences when making decisions about what information to share (Marwick \& boyd, 2010). Understanding teachers' uses of Twitter, therefore, requires an understanding of how teachers create and respond to structures about what types of content and information should be shared on the medium. Applied to Twitter, this view on structure raises questions that a narrow focus on materiality is unable to answer.

\section{What Can Sociomateriality Teach Us?}

Recognizing the sociomateriality of a technology involves directing attention to the values, contexts, and relationships that shape use. Accordingly, the sociomateriality of Twitter raises three kinds of questions that might influence the nature of teacher professional communities online. What these questions have in common 
is the recognition that the perception of both enabling and constraining structures drive innovations in practice.

The first question relates to what kinds of adaptations that teachers might make when using Twitter. Assuming that achieving meaningful or robust sense of professional community is the goal, how do teachers get Twitter to deliver what they want? After all, Twitter might be seen as rather limited. One hundred and forty characters is short: the present sentence is 141 characters and it does not incorporate hashtags or other conventions. What's more, a single, constantly streaming screen of information might come across as disorganized or overwhelming.

In other words, technologies can introduce cognitive burdens that make some information more difficult to understand (Ferran \& Watts, 2008), and users must make decisions about how particular technologies fit their communication goals (Daft, Lengel, \& Trevino, 1987). Teachers who prioritize a richer channel of information (Daft et al., 1987) or who have multiple communication goals (Watson-Manheim \& Bélanger, 2007) might not perceive Twitter's basic features to be sufficient. If social connection or sharing the craft of teaching are among the goals of teachers on Twitter, then 140-character tweets seem to be shallow vessels. Some other mechanism might be needed to boost one's satisfaction with the information at hand.

Thus, the motivation to create a meaningful sense of professional community on Twitter might "spill over" into activities beyond the realm of Twitter. Such activities might include blogging out their thoughts, conducting school visits with other Twitter users, or chatting via phone or video. Teachers' online professional communities might not simply be about being online.

The second question relates to what kinds of topics teachers will be willing to address on Twitter. Are some topics "safer" than others? Some teachers might feel that certain topics are socially taboo, while others might not want to risk negative reactions from supervisors or colleagues. As a result, there could be implicit limitations on the professional development topics that can be addressed through Twitter. Additionally, the interactivity of the Twitter audience and its ability to both suggest and enforce social norms could also be leading to a "herding" effect where individuals only ask questions or express opinions that they feel will be validated by other users (Kietzmann, Silvestre, McCarthy, \& Pitt, 2012). Indeed, Twitter users are more likely to retweet information or articles that match the expectations of their imagined audience (boyd et al., 2010). Although these are "people issues" that do not negate the possibility for teachers to learn from each other online, they do elevate 
the importance of examining what is and is not communicated among people in these communities.

Finally, the third question relates to the structure of ties among educators. Does it matter that ties aren't reciprocal? Proponents for Twitter argue that it provides teachers with access to an almost unlimited pool of colleagues (Burden, 2010). However, such ties are typically only "one-way" (Kwak et al., 2010; Holmes, 2011) and feedback about who is listening or benefiting might be difficult to discern. Some users might prefer to "lurk" in communities, perusing communications without posting anything themselves (Kozinets, 2009). In other words, if professional communities benefit from dialogue, then concerns remain about whether and how such dialogue actually occurs. What's more, concerns might also be raised about what kinds of tweets get prioritized in such a system. Marwick and boyd (2010) describe how a sense of "micro-celebrity" led users to tailor their tweets in order to maximize their potential reach and popularity among followers. As a result, relationships between teachers on Twitter may not have the same characteristics that they would in offline professional learning communities.

\section{Discussion and Conclusion}

In the preceding passages we have described different ways to think about and to understand Twitter's potential contributions to teacher professional communities online. We argued that simply focusing on the material characteristics of a technology only provides a portion of the picture about how a technology might be used. Accordingly, we suggest that it may be time for educational scholars and practitioners to think bigger. We attempted to provide theoretical contributions toward this end by describing how the sociomaterial and "people issues" around Twitter might refine one's understanding about its potential role in teachers' professional growth. Although Twitter serves as an important venue for such thinking, the lessons around sociomateriality could apply to broader discussions of how educational change occurs.

For example, we suggested teachers' drive to develop a meaningful sense of professional learning might lead teachers to innovate new routines and practices beyond the realm of Twitter (e.g., face-to-face interactions, blogs, video chats). This idea of developing a repertoire is worth examining, not only as it relates to Web 2.0 technologies, but also other school activities. For example, teachers often have 
a repertoire of technologies for delivering assessment and student information (Wayman, Cho, \& Richards, 2010). It's plausible that the introduction of new data and new systems might present educators with new demands around how to interpret students' needs. In turn, these might spill over into new routines and advice networks around data or computer data systems.

We also suggested that social factors may influence the overall marketplace of ideas shared by Twitter users. If the content and dialogue in a professional community online is advertently narrowed, what does this mean for its quality? While the potential for celebrity and status might be possible in traditional school-based learning communities, the online context increases the likelihood that teachers might make decisions about the quality of a contributor without the benefit of direct observation or interaction. Future research might compare knowledge sharing within online professional communities with knowledge sharing in conventional communities. What is really being learned? How do teachers make decisions about who to collaborate with and who to learn from? Do the relationships developed online endure meaningfully? While technologies might enhance some forms of learning, for others they might only serve as a quick and shallow fix.

Just as scholars may need to evaluate what knowledge is being shared online, it may also be important to examine what actually happens with that knowledge in everyday practice. Do technologies really support changes in what teachers do or see in the world? If so, how do teachers decide what knowledge online is meaningful and practical? It is not uncommon for people to orient only toward "evidence" that confirms pre-existing biases (Coburn, Honig, \& Stein, 2009; Pfeffer \& Sutton, 2000). If this confirmation bias holds true in online communities, then practitioners might not even realize that their sense of reward and benefit is not necessarily based in "learning." Future research needs to look beyond the potential of Twitter toward whether its promises are actually being fulfilled.

Recognizing the sociomaterial dimensions of technologies, researchers may be better able to account for what contributions are best attributed to the technology itself. Equally important, this perspective may provide scholars with more nuanced ways to understand educational change and progress. Rather than focusing on broad stroke measures, like policy or technology, they might be better served by attending to how people come to perceive affordances or constraints around those resources. These issues may be at the heart of how and why policies and technologies are rejected or adapted (Cho \& Wayman, in press; Davidson \& Chismar, 2007; Spillane, Reiser, \& Reimer, 2002)_people, and not simply technologies, are the real agents of change. 


\section{References}

Bailey, D. E., \& Barley, S. R. (2011). Teachinglearning ecologies: Mapping the environment to structure through action. Organization Science, 22(1), 262-285.

Barkley, C. K. A. (2012). School leader use of social media for professional discourse (Doctoral dissertation, Virginia Commonwealth University). Retrieved from http://search. proquest.com.proxy.bc.edu/pqdtft/docv iew/1038969892/13A76323B8119221CE6/ 1 ? accountid $=9673$

Barth, R. S. (1990). Improving schools from within. New York: Jossey-Bass.

boyd, d., Golder, S., \& Lotan, G. (2010). Tweet, tweet, retweet: Conversational aspects of retweeting on Twitter. Presented at the HICSS-43, Kauai, HI: IEEE.

Brooks, C. (2011). Locating leadership: The blind spot in Alberta's technology policy discourse. Education Policy Analysis Archives, 19(26), Retrieved from http://epaa.asu. edu/ojs/article/view/910.

Brown, J. S., \& Duguid, P. (1991). Organizational learning and communities-of-practice: Toward a unified view of working, learning, and innovation. Organization Science, 2(1), 40-57.

Burden, K. J. (2010). Conceptualising teachers' professional learning with Web 2.0. Campus-Wide Information Systems, 27(3), 148-161. doi:10.1108/10650741011054456

Cho, V., \& Wayman, J.C. (in press). Districts' efforts for data use and computer data systems: The role of sensemaking in system use and implementation. Teachers College Record.

Coburn, C. E., Honig, M. I., \& Stein, M. K. (2009). What's the evidence on districts' use of evidence? In L. J. Bransford, D. J. Stipek, N. J. Vye, L. M. Gomez, \& D. Lam (Eds.), The Role of Research in Educational Improvement (pp. 67-88). Cambridge: Harvard Education Press.

Couros, A., \& Jarrett, K. (2012). Twitter. In S. McLeod \& C. Lehmann (Eds.), What School Leaders Need to Know About Digital Technologies and Social Media (pp. 147-152). San Francisco: Jossey-Bass.
Daft, R., Lengel, R.H., \& Trevino, L.K. (1987) Message equivocality, media selection, and manager performance: Implications for information systems. MIS Quarterly, 11(3), 355-366.

Davidson, E. J., \& Chismar, W. G. (2007). The interaction of institutionally triggered and technology-triggered social structure change: An investigation of computerized physician order entry. MIS Quarterly, 31(4), 739-758.

DeSanctis, G., \& Poole, M. S. (1994). Capturing the complexity in advanced technology use: Adaptive structuration theory. Organization Science, 5(2), 121-147.

Dufour, R. (2004). What is a "Professional Learning Community"?. Educational Leadership, 61(8), 6-11.

Ferran, C., \& Watts, S. (2008). Videoconferencing in the field: A heuristic processing model. Management Science, 54(9), 1565-1578.

Forte, A., Humphreys, M., \& Park, T. (2012). Grassroots professional development: How teachers use Twitter. In Proceedings of the Association for the Advancement of Artificial Intelligence (pp. 106-113). Presented at the International Conference on Weblogs and Social Media, Dublin, Ireland: Association for the Advancement of Artificial Intelligence.

Fullan, M. (2002). The role of leadership in the promotion of knowledge management in schools. Teachers and teaching: theory and practice, 8(3/4), 409-419.

Goffman, E. (1959). The presentation of self in everyday life. New York: Doubleday.

Greenhow, C., Robelia, B., \& Hughes, J. E. (2009). Web 2.0 and classroom research: What path should we take now? Educational Researcher, 38(4), 246-259. doi:10. 3102/0013189X09336671

Hamilton, L., Halverson, R., Jackson, S. S., Mandinach, E., Supovitz, J. A., \& Wayman, J. C. (2009). Using student achievement data to support instructional decision making (Practice guide No. NCEE 2009-4067). National Center for Education Evaluation 
and Regional Assistance, Institute of Education Sciences, U.S. Department of Education. Retrieved from http:// www.eric.ed.gov/ERICWebPortal/detail ?accno=ED506645

Hargreaves, A., \& Fink, D. (2006). Sustainable leadership. CA: Jossey-Bass.

Hew, K. F., \& Hara, N. (2007). Empirical study of motivators and barriers of teacher online knowledge sharing. Education Technology Research and Development, 55(6), 573-595.

Holmes, D. (2011). What is 'social' about social media. Communications \& Convergence Review, 3(2), 105-115.

Honeycutt, C., \& Herring, S. C. (2009). Beyond microblogging: Conversation and collaboration via Twitter. In Proceedings of the Forty-Second Hawai'i International Conference on System Sciences. Presented at The Forty-Second Hawai'i International Conference on System Sciences, Los Alamitos, CA: IEEE Press.

Howard, P. N., Duffy, A., Freelon, D., Hussain, M., Mari, W., \& Mazaid, M. (2011). Opening closed regimes: What was the role of social media during the Arab Spring. Seattle, WA: Project on Information Technology and Political Islam, University of Washington.

Hughes, J. E., \& Narayan, R. (2009). Collaboration and learning with wikis in post-secondary classrooms. Journal of Interactive Online Learning, 8(1), 63-81.

Jones, M. R., \& Karston, H. (2008). Giddens's structuration theory and information systems research. MIS Quarterly, 32(1), 127-157.

Kietzmann, J.H., Silvestre, B.S., McCarthy, I.P., \& Pitt, L. (2012). Unpacking the social media phenomenon: Towards a research agenda. Journal of Public Affairs, 12(2), 109-119.

Kozinets, R. V. (2009). Netnography: Doing ethnographic research online. Sage Publications Ltd.

Kwak, H., Lee, C., Park, H., \& Moon, S. (2010). What is Twitter, a social network or a news media? In Proceedings of the 19th International Conference on Word Wide Web (pp. 591-600). Presented at the WWW 2010, Raleigh, NC: International Word Wide Web Conference Committee.
Leonardi, P. M. (2009). Why do people reject new technologies and stymie organizational changes of which they are in favor? Exploring misalignments between social interactions and materiality. Human Communication Research, 35, 407-441.

Leonardi, P. M. (2012). Materiality, sociomateriality, and socio-technical systems: What do these terms mean? How are they related? Do we need them? In P. M. Leonardi, B. A. Nardi, \& J. Kallinikos (Eds.), Materiality and Organizing: Social Interaction in a Technological World (pp. 25-48). Oxford: Oxford University Press. Retrieved from http://papers.ssrn.com/sol3/papers. cfm?abstract_id=2129878

Li, S., Li, S., \& Sun, H. (2012). The application of Web 2.0 technologies to construct an online community environment in the promotion of teacher peer-coaching. International Journal of Continuing Education and Lifelong Learning, 4(2), 101-116.

Lieberman, A. (2000). Networks as learning communities: Shaping the future of teacher development. Journal of Teacher Education, 51(3), 221-227.

Litt, E. (2012). Knock, knock. Who's there? The imagined audience. Journal of Broadcasting \& Electronic Media, 56(3), 330-345.

Marwick, A. E., \& boyd, d. (2010). I tweet honestly, I tweet passionately: Twitter users, context collapse, and the imagined audience. New Media \& Society, 13(1), 114-133. doi:10.1177/1461444810365313

McDaniel, R. R., \& Weick, K. E. (1989). How professional organizations work: Implications for school organization \& management. In Schooling for Tomorrow: Directing Reforms to Issues That Count. Boston: Allyn and Bacon.

McLaughlin, M.W., \& Talbert, J. E. (2006). Building school-based teacher learning communities: Professional strategies to improve student achievement. NY: Teachers College Press.

Means, B., Padilla, C., DeBarger, A., \& Bakia, M. (2009). Implementing data-informed decision making in schools: Teacher access, supports and use. Washington, DC: U.S. Department of Education, Office of Planning, Evaluation and Policy Development. 
Nash, J. (2011). A tale of two forms: One professor's path to improve learning through a common online teaching tool. Journal of Research on Leadership Education, 6(5), 181-194.

Nonaka, I. (1994). A dynamic theory of organizational knowledge creation. Organization Science, 5(1), 14-37.

Nussbaum-Beach, S., \& Hall, L. R. (2012). The connected educator: Learning and leading in a digital age. Bloomington, IN: Solution Tree.

Orlikowski, W. J. (1992). The duality of technology: Rethinking the concept of technology in organizations. Organization Science, 3(3), 398-427.

Orlikowski, W. J. (1996). Improvising organizational transformation over time: A situated change perspective. Information Systems Research, 7(1), 63-92.

Orlikowski, W. J. (2000). Using technology and constituting structures: A practice lens for studying technology in organizations. Organization Science, 11(4), 404-428.

Orlikowski, W. J., \& Barley, S. R. (2001). Technology and institutions: What can research on information technology and research on organizations learn from each other? MIS Quarterly, 25(2), 145-165.

Orlikowski, W. J., \& lacono, C. S. (2001). Research commentary: Desperately seeking the "IT" in IT research - A call to theorizing the IT artifact. Information Systems Research, 12(2), 121-135.

Pfeffer, J., \& Sutton, R. I. (2000). The knowingdoing gap. Boston: Harvard Business School Press.

Pinch, T. J., \& Weibe, E. B. (1984). The social construction of facts and artefacts: Or how the sociology of science and the sociology of technology might benefit each other. Social Studies of Science, 14, 399-441.

Richardson, W., \& Mancabelli, R. (2011). Personal learning networks: Using the power of connections to transform education. Bloomington, IN: Solution Tree.
Schlager, M. S., Farooq, U., Fusco, J., Schank, P., \& Dwyer, N. (2009). Analyzing online teacher networks: Cyber networks require Cyber research tools. Journal of Teacher Education, 60(1), 86-100.

Schlenker, B.R. (1980). Impression management: The self-concept, social identity, and interpersonal relations. Monterey, CA: Brooks/ Cole Publishing Company.

Spillane, J. P., Reiser, B. J., \& Reimer, T. (2002). Policy implementation and cognition: Reframing and refocusing implementation research. Review of Educational Research, 72(3), 387-431. doi:10. 3102/00346543072003387

Talbert, J. E. (2010). Professional learning communities at the crossroads: How systems hinder or engender change. In A. Hargreaves, A. Lieberman, M. Fullan, \& D. Hopkins (Eds.), Second International Handbook of Educational Change (pp. 555571). Dordrecht: Springer Netherlands. Retrieved from http://rd.springer.com/ chapter/10.1007/978-90-481-2660-6_32

Twitter. (2012). Welcome to your new home. Twitter Help Center. Retrieved from https:// support.twitter.com/articles/20169520\#

Watson-Manheim, M., \& Bélanger, F. (2007) Communication media repertoires: Dealing with the multiplicity of media choices. MIS Quarterly, 31(2), 267-293.

Wayman, J. C., Cho, V., \& Johnston, M. T. (2007). The data-informed district: A districtwide evaluation of data use in Natrona County School District.

Wayman, J. C., Cho, V., \& Richards, M. P. (2010). Student data systems and their use for educational improvement. In P. L. Peterson, E. Baker, \& B. McGraw (Eds.), International Encyclopedia of Education (Vol. 8, pp. 14-20). Oxford: Elsevier.

Wayman, J. C., Stringfield, S., \& Yakimowski, M. (2004). Software enabling school improvement through analysis of student data (No. 67). Center for Research on the Education for Students Placed At Risk. 


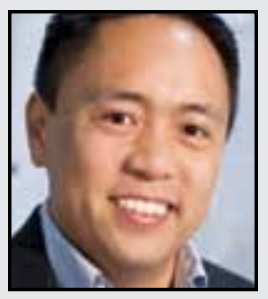

Vincent Cho, Ph.D., is an Assistant Professor of Educational Leadership at Boston College. His other experiences include being a Teach for America corps member, assistant principal, and legislative aide in the Texas Senate. Currently, Cho studies the technologies, leadership practices, and district policies that support the effective use of data and information. His aim is to help schools and educators make the most out of their knowledge about students. His recent publications include the ninth edition of Supervision: A Redefinition, published by McGraw-Hill and co-authored with Thomas J. Sergiovanni and Robert J. Starratt.

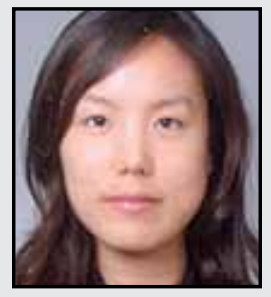

Jina Ro is a doctoral student in Curriculum and Instruction, at Boston College. She received her B.A. and M.A. in Education at Ewha Womans University at Seoul, Korea. In addition to her experience as a middle school English teacher in Korea, she also served as an intern at the United Nations Educational, Scientific, and Cultural Organization. There, she provided administrative and technological support for the Section for Teacher Education. Her research interests include qualitative and mixed methods research on teacher learning, school reform, and secondary preservice teacher education.

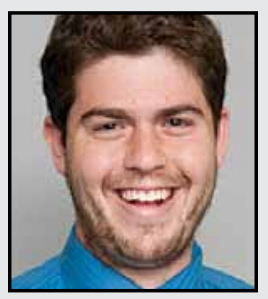

Josh Littenberg-Tobias is a doctoral student in Educational Research, Measurement, and Evaluation at Boston College. Specifically, he studies adolescent and young adult civic engagement. His current focus is on using sophisticated statistical models to identify different factors that affect how young people engage in their communities. Additionally, he would like to further explore the role that technology plays in youth civic engagement. He has worked on many different projects related to youth civic engagement including immersive service-learning programs, college students' understanding of social justice, and state civic education requirements.

LINK TO:

http://www.vincentcho.com 